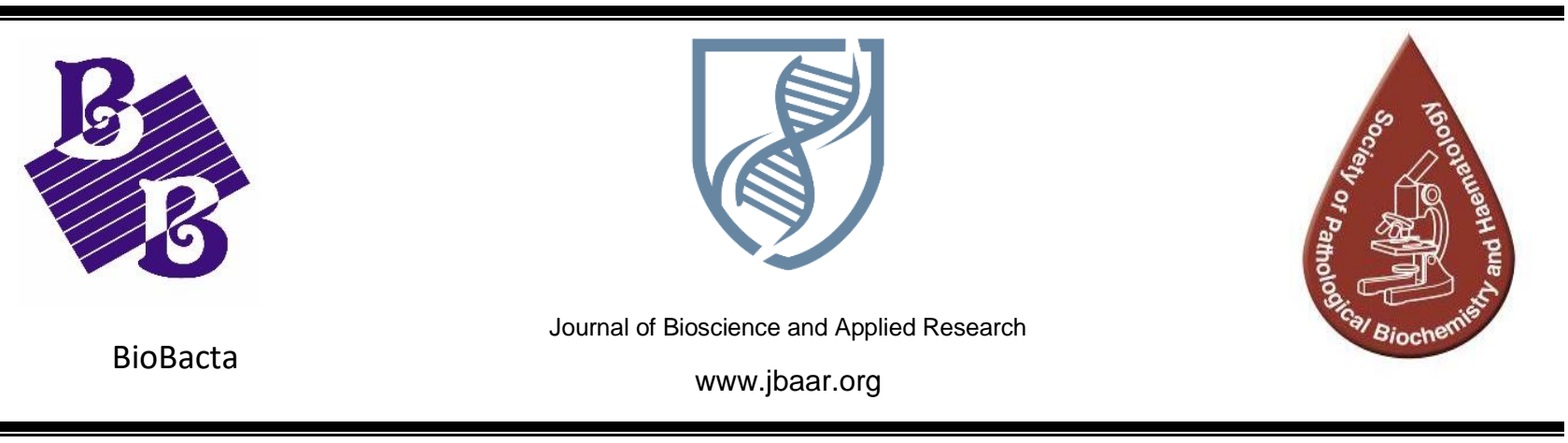

\title{
Detection of Bacterial Pathogen from Wound Infections and Study Some of their Virulence Factors
}

\author{
Noor Hamid Abbas Al- Marzoog and Amal Hesham Hameed
}

Department of the pathological analysis technique. Al-Mustaqbal College University, Iraq

DOI: 10.21608/jbaar.2018.155991

\begin{abstract}
Wound infections are one of the most important and potentially serious complications that occur in the acute period following injury. In this study, (35) wound swaps were collected from (35) patients with suspected wound infection, during the period from December (2017) to March (2018). The results of this study revealed that $(74.29 \%)$ of samples were positive for bacterial culture, while $(25.71 \%)$ of a sample have no growth. The bacterial culture has shown that (38.46\%) (10 isolates) of bacterial isolates were Staphylococcus aureus followed by Pseudomonas spp. (19.23\%) (5 isolate), E. coli (19.23\%) (5 isolate), Klebsiella (15.38\%) (4 isolate) and Proteus (7.69\%) (2 isolate). In-vitro, the susceptibility of bacteria towards some antibiotics included in this study revealed that the Ciprofloxacin, are the most effective antibiotics to different types of pathogenic bacteria, while all bacteria were resistant to Ampicillin.
\end{abstract}

Key Words: Wound swap, bacterial infection, virulence factor, antibiotics

\section{Introduction}

Wound infection is a common problem (Giacometti et al., 2000). Infection of the wound happened due to entry of the bacteria through breached skin. These bacteria stop healing and produce signs and symptoms. Multiple organisms can cause wound infection (Melling et al., 2001). Most wound infections can be classified into two major categories: skin and soft tissue infections, although they often overlap as a consequence of disease progression. Infections of hospital-acquired wounds are among the leading nosocomial causes of morbidity and increasing medical expense (Cutting and White, 2004).
Diagnosis of wound infection is an important part of wound care, as infection can cause a wound to stall in the healing process, or even enlarge. The signs of infection (redness, swelling, increased drainage, increased pain) and be proactive in assessing and diagnosing infection.

Swab cultures are the most commonly used method to culture wound infections because they are easy to perform, do not cause trauma to the wound bed, and avoid a surgical procedure that can result in complications. Swab cultures, sample the wound surface, along with small amounts of wound fluid expressed from the wound or obtained from areas of tunneling or undermining, to quantify the amount/number and type of bacteria present on a 
wound (the wound needs to be cleansed before swabbing takes place) (Meyers, 2008).

For the treatment of infection, a large number of antibiotics are used. Both broadspectrum and narrow-spectrum antibiotics are available nowadays. It is ideal to give proper antibiotics after culture and sensitivity of the wound swab, pus, or infected tissue. Unfortunately, this practice is uncommon among physicians, especially in developing countries. Improper and irrational use of antibiotics and genetic and non-genetic drugresistant mechanisms of bacteria lead to drug resistance. Drug-resistant bacteria are the most important therapeutic challenge in the field of infectious diseases, many of them are multi-drug resistant (Atiyeh et al., 2007).

\section{Material and Methods}

\subsection{Patient}

Table (3-1) Type of virulence factors detected in bacterial isolates

\begin{tabular}{|c|c|c|c|c|c|}
\hline $\begin{array}{c}\text { Bacterial } \\
\text { isolates }\end{array}$ & capsule & hemolysin & Protease & CFA I & CFA III \\
\hline S.aureus & + & + & + & - & + \\
\hline Pseudomonas & + & + & + & - & - \\
\hline Klebsiella spp. & + & - & $+(3)$ & + & + \\
\hline E.coli & + & + & + & + & + \\
\hline Proteus & - & + & + & - & + \\
\hline
\end{tabular}

The ability of S.aureus isolate to produce some virulence factors was investigated and the results are shown in table (3-1). S. aureus isolates had shown to possess the polysaccharide capsule which was an important component in the pathogenesis and enhances bacterial virulence by modulating $S$. aureus adherence to endothelial surface in vitro, this agrees with the result mentioned by Nair et al., (2000).

In this study, $S$. aureus isolate $(100 \%)$ could produce the hemolysin, and the type of
This study includes 35 patients with wound infection during the period from December (2017) to March (2018). The samples were collected using sterile cotton swabs from patients clinically diagnosed with wound infection.

\subsection{Identification of isolated bacteria}

Identification of isolated bacteria was carried out by using culture methods and biochemical tests. The samples were the first culture on Blood agar and MacConkey agar then incubated for $\left(24 \mathrm{~h}\right.$. at $\left.37^{\circ} \mathrm{c}\right)$ after that the bacterial growth was diagnosed by using specific culture and biochemical tests.

\section{Result and Discussion}

\subsection{Detection of virulence factors}

The ability of different types of bacterial isolates to produce some virulence factors was investigated and the results are shown in Table (3-1) 
and staphopain) which are important virulence factors and controlling the gene expression for this enzyme by regulator factors.

The ability of Staphylococcus aureus to produce colonization factor antigen was tested and it was noted that $(100 \%)$ of isolate could produce colonization factor antigen III (CFA III).

E. coli isolate were tested for their ability to produce capsule and it was found that $(100 \%)$ from these isolate could produce the polysaccharide capsule. Silver and Vimr, (1990) demonstrated that some capsules have been correlated with pathogenic strains of E. coli.

Hemolysin production by E. coli was studied, and it was found that $(100 \%)$ of the isolate was able to produce $\alpha$-hemolysin on a blood agar plate.

These results agree with Herlax et al., (2010) who pointed that $\alpha$ - hemolysin (Hly A) is an extracellular toxin secreted by $E$. coli, targeting to plasma membranes of eukaryotic cells. It has been found that this toxin is released to external media associated with bacterial outer membrane vesicles (OMVs).

The erythrocytes are not only affected by hemolysin, but also leucocytes (white blood cells). E. coli hemolysin is potentially cytotoxic to monocytes, lymphocytes, and macrophages leading them to autolysis and death (Al-Hasson, 2010).

Concerning protease, the ability of $E$. coli to produce extracellular protease in $\mathrm{M}_{9}$ media was investigated, and it was found that all these isolates (100\%) could produce extracellular protease after 24 hours of incubation table (3-1). A clear hallo of the transparent area was found around the colony after the addition of $3 \mathrm{ml}$ of $3 \%$ trichloroacetic acid. This result was identical to that obtained by Baron, (1994). Extracellular protease plays an important role in cell survival and cell-cell communication (Abhrajyoti et al., 2009).

The ability of E. coli to produce colonization factor antigen was tested and it was noted that $(100 \%)$ of isolate could produce colonization factor antigen I (CFA I) and colonization factor antigen III.

The ability of Klebsiella spp. isolates to produce some virulence factors were investigated and the results are shown in table (3-1). From these results, it could be noticed that all Klebsiella spp. isolates possessed the polysaccharide capsule which surrounds the bacterial cell. This result agrees with the result obtained by Podschun and Ulmann, (1998) who had pointed that the diagnostic feature for Klebsiella is a capsular polysaccharide, and it's an essential virulence factor for K. pneumoniae.

The results also showed that all Klebsiella spp. isolates could not produce hemolysin extracellular when cultured on blood agar, and the type of hemolysis was gamma hemolysis because there was no hemolysis present on blood agar plates.

Klebsiella spp. isolates were positive (75\%) (3 isolates) to produce extracellular protease. These results agreed with Bondarenko et al., (2000) who found that $(58.6 \%)$ of Klebsiella are with the presence of SIg-A protease activity, which made this enzyme play an important role in the pathogenicity of this bacteria.

The ability of these bacteria to produce CFAI, CFA III was studied, CFA/1 was investigated 
in the presence of D-mannose and human erythrocyte group $\mathrm{A}$, and it was found that all isolates $(100 \%)$ can produce CFAI and CFAIII. This means that it is so-called mannose resistant hemagglutination-assay positive, however, the presence of mannose resistant adhesion factor may help the bacteria in adhesion to the epithelial cells, and then enhance the pathogenicity of bacteria(ALZaag.,1994).

Also Pseudomonas spp. was tested for capsule and protease production and the result show that all isolate was positive for capsule production and protease. Surface structures, including pili and the polysaccharide capsule or glycocalyx, appear to mediate the initial attachment of $P$. aeruginosa to its prospective host, thus permitting colonization. Extracellular enzymes such as alkaline protease, elastase, phospholipase $\mathrm{C}$, and exotoxin A degrade infected tissues and promote bacterial invasion (Pollack, 1984).

\subsection{Antimicrobial susceptibility pattern of bacterial isolates}

The susceptibility of the recovered bacterial isolates to antibiotics was determined using disc diffusion assay, Kirby-Bauer method. The results obtained showed that the organisms varied in their susceptibility to all the antimicrobials used. The majority of them showed multi-resistances.

Table (3-2) Antimicrobial susceptibility patterns of bacterial isolates

\begin{tabular}{|c|c|c|c|c|c|}
\hline \multirow{2}{*}{\begin{tabular}{c} 
Bacterial isolates \\
\cline { 2 - 6 }
\end{tabular}} & \multicolumn{5}{|c|}{ Antibiotics } \\
\cline { 2 - 6 } $\begin{array}{c}\text { Staphylococcus } \\
\text { aureus }\end{array}$ & $\mathrm{R}$ & $\mathrm{S}$ & $\mathrm{R}$ & $\mathrm{R}$ & $\mathrm{R}$ \\
\hline Pseudomonas spp & $\mathrm{R}$ & $\mathrm{S}$ & $\mathrm{R}$ & $\mathrm{R}$ & $\mathrm{R}$ \\
\hline Klebsiella & $\mathrm{R}$ & $\mathrm{S}$ & $\mathrm{R}$ & $\mathrm{R}$ & $\mathrm{R}$ \\
\hline E. coli & $\mathrm{R}$ & $\mathrm{S}$ & $\mathrm{S}$ & $\mathrm{R}$ & $\mathrm{R}$ \\
\hline Proteus & $\mathrm{S}$ & $\mathrm{S}$ & $\mathrm{R}$ & $\mathrm{R}$ & $\mathrm{S}$ \\
\hline
\end{tabular}

CN: Gentamicin, CIP: Ciprofloxacin, AM: Ampicillin, C: Chloramphenicol, AK: Amikacin 


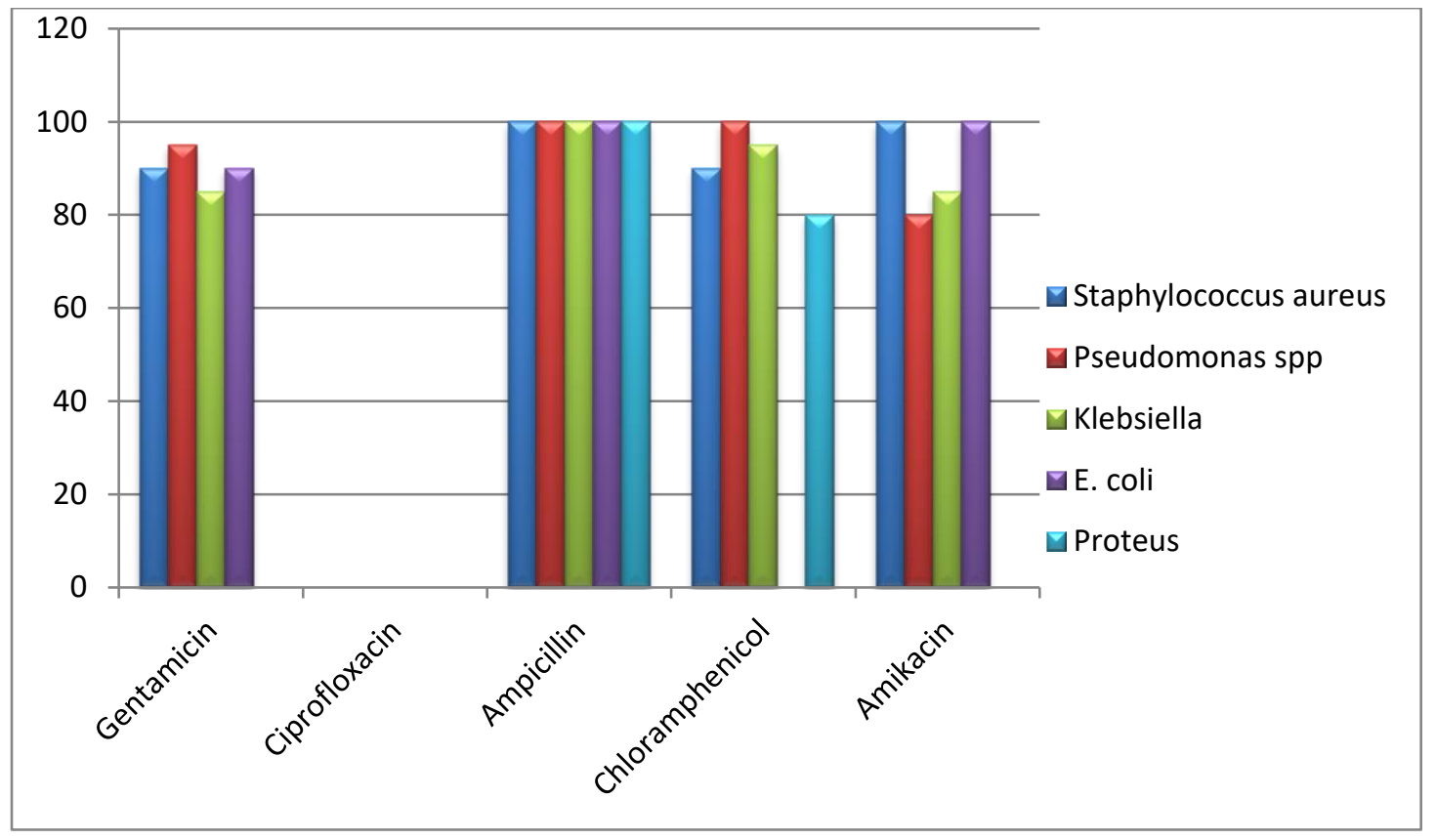

Among the isolated pathogens all of them shows $100 \%$ sensitivity towards Ciprofloxacin. While bacteria show different resistance rates to Amikacin, Gentamycin, and Chloramphenicol. While all isolates were resistant $100 \%$ toward Ampicillin.

All of the isolated bacteria were resistant to ampicillin. This may be due to the antibiotics have been in use for a much longer time and their oral route of administration that affects their rate of absorption into the bloodstream.

The results of antimicrobial sensitivity showed that $S$. aureus was highly resistant for most of the antibiotics tested, while it had less resistance to ciprofloxacin. The adaptation of $S$. aureus to the modern hospital environment has been marked by the acquisition of drug resistance genes soon after antibiotic introduction (Bouchillon et al., 2004).

Also, the results showed that Pseudomonas spp was highly resistant for most of the antibiotics tested. This result was in agreement with the study done by Manyahi, (2012).
Increasing resistance to various antiPseudomonas agents has been reported worldwide and this poses a serious problem in the therapeutic management of $P$. aeruginosa infections (Brown and Izundu, 2004).

\section{References}

- Abhrajyoti, G., Krishanu, C. and Dhrubajyoti, C. (2009). Cloning of Feather degradation minor extracellular protease from Bacillus cereus DCUW: dissection of the structural domains. Microbiol., 155: 2049-2057.

- Al-Hasson, H.F.A. (2010). Characterization and purification of hemolysin produced by uropathogenic Escherichia coli. MSc. Thesis College of Medicine, University of Babylon.

- Al-Zaag, A. (1994). Molecular Biology of Bacterial Virulence 1th Ed. Baghdad University.

- Atiyeh, B.S., Costagliola, M., Hayek, SN. and Dibo, SA. (2007). Effect of silver on burn wound infection control and healing: a 
review of the literature. burns. 33(2):13948.

- Baron, E. J., Peterson, L. R. and Finegold, S. M. (1994). Bailey and Scott's Diagnostic Microbiology. $9^{\text {th }}$ Ed. The C.V. Mosby Company, U.S.A.

- Bondarenko, VM., Aqapova, OV. and Vinogradov, NA. (2000). Role of bacterial protease degrading secretory immunoglobulin $\mathrm{A}$ in Klebsiella persistence. $\mathrm{Zh}$ Mikrobiol Epidemiol Immunobiol. 4:12-16.

- Bouchillon, SK., Johnson, BM. and Hoban, DJ. (2004). Determining incidence of extended-spectrum beta-lactamaseproducing Enterobacteriaceae, vancomycin-resistant Enterococcus faecium, and methicillin-resistant Staphylococcus aureus in 38 centers from 17 countries: the PEARLS study 20012002. Int J Antimicrob Agents. 24(2): 119124.

- Brown, PD. and Izundu, A. (2004). Antibiotic resistance in clinical isolates of Pseudomonas aeruginosa in Jamica .Rev Panam Salud Publica. 16(2): 125-130.

- Cutting, KF. and White, R. (2004). Defined and refined: criteria for identifying wound infection revisited. Br J Community Nurs. 9(3): S6-15.

- Dinges, M. M.; Orwin, P. M. and Schlievert, P. M. (2000). Exotoxins of Staphylococcus aureus. J. Clin. Microbiol. 13(1):16-34.

- Giacometti, A., Cirioni, O., Schimizzi, A., Del Prete, M., Barchiesi, F. and D'errico, M. (2000). Epidemiology and microbiology of surgical wound infections. Journal of clinical microbiology. 38(2):918-22.

- Herlax, V., Hennig, M., Bernasconi, A., Goni, F., and Bakas, L. (2010). The lytic mechanism of Escherichia coli $\alpha$ hemolysin associated to outer membrane vesicles. Health, 2 (5): 484-492.

- Karlsson, A. and Arvidson, S. (2002) . Variation in extracellular protease production among clinical isolates of Staphylococcus aureus due to different levels of expression of the protease repressor sarA. Infect. Immune. 70 (8): 4239-4246.

- Manyahi, J. (2012). Bacteriological spectrum of post-operative wound infections and their antibiogram in a tertiary hospital, Dar es Salaam, Tanzania. Muhimbili University of Health and Allied Sciences. (PhD thesis).

- Melling, AC., Ali, B., Scott, EM. and Leaper, DJ. (2001). Effects of preoperative warming on the incidence of wound infection after clean surgery: a randomised controlled trial. The Lancet. 358(9285):876-80.

- Meyers, B. (2008). Wound Management: Principles and Practice. $2^{\text {nd }}$ edition. Pearson Prentice Hall. Upper Saddle River, New Jersey. pg. 100-102.

- Nair, S. P.; Williams, R. J., and Henderson, B. (2000). Advance in our understanding of the bone and joint pathology caused by Staphylococcus aureus infection. Rheumatol. 39: 821-834.

- Podschun, R. and Ulmann, U. (1998). Klebsiella spp. as nosocomial pathogens: Epidemiology, Taxonomy, Typing methods 
and Pathogenicity factors. Clin. Microbial.

Rev. 11(4): 589-603.

- Pollack, M. (1984). The Virulence of Pseudomonas aeruginosa. Reviews of Infectious Diseases, Volume 6, Issue Supplement_3, 1 September 1984, Pages S617-S626.

- Silver, R. P., and Vimr, E. R. (1990). Polysialic acid capsule of E. coli K1, p. 3960. In The bacteria, vol. 11. Molecular basis of bacterial pathogenesis. Academic Press, Inc., New York, N.Y. 